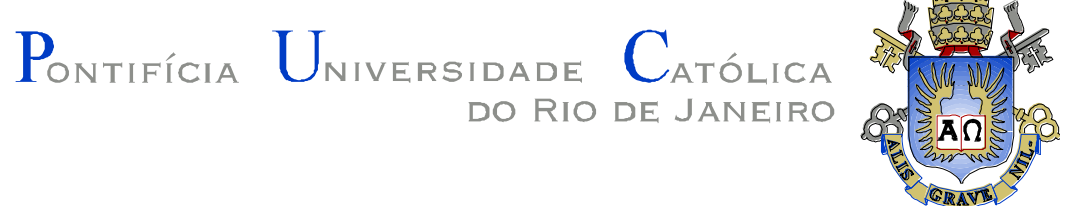

Lukas Lui

\begin{abstract}
A IGREJA DO ESPÍRITO DE DEUS QUE NASCE NO CORAÇÃO DO POVO.

A relevância e o desafio do sensus fidei na Constituição dogmática Lumen Gentium do Vaticano II
\end{abstract}

Dissertação de Mestrado

Dissertação apresentada como requisito parcial para a obtenção do grau de Mestre pelo Programa de PósGraduação em Teologia do Departamento de Teologia da PUC-Rio.

Orientadora: Prof ${ }^{\mathrm{a}}$. Ana Maria Azeredo Tepedino

Rio de Janeiro Agosto de 2010 


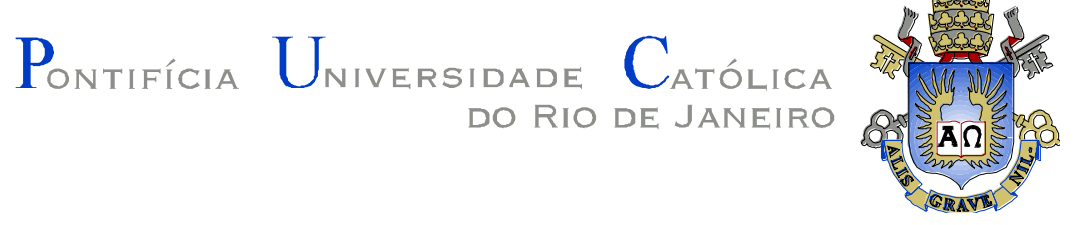

Lukas Lui

\section{A Igreja do Espírito de Deus que nasce no coração do povo. A relevância e o desafio do sensus fidei na Constituição dogmática Lumen Gentium do Vaticano II}

Dissertação apresentada como requisito parcial para a obtenção do grau de Mestre pelo Programa de PósGraduação em Teologia do Departamento de Teologia da PUC-Rio.Aprovada pela Comissão Examinadora abaixo assinada.

Prof. ${ }^{\text {a }}$ Ana Maria A. L. Tepedino

Orientadora

Departamento de Teologia - PUC-Rio

Prof.Abimar Oliveira de Moraes

Departamento de Teologia - PUC-Rio

Prof.Nelson Francelino Ferreira

Faculdade de São Bento do Rio de Janeiro

Prof. - Denise Berruezo Portinari

Coordenadora Setorial da pós-graduação do Centro de

Teologia e Ciências humanas - PUC-Rio

Rio de Janeiro, 12 de agosto de 2010. 
Todos os direitos reservados. É proibida a reprodução total ou parcial do trabalho sem autorização da universidade, do autor e da orientadora.

\section{Lukas Lui}

Cursou a gestão pastoral e filosofia no IMACH (Instituto Marista de Ciências Humanas - Belo Horizonte) em 1998. Graduou-se em Teologia Sistemática no ISTA (Instituto Santo Tomás de Aquino - Belo Horizonte) em 2004. Participou de diversos congressos, nacionais e internacionais, na área de teologia. Responsável pela formação inicial dos seminaristas da Congregação dos Fráteres de Nossa Senhora, Mãe de Misericórdia.

Ficha Catalográfica

Lui, Lukas

A Igreja do Espírito de Deus que nasce no coração do povo: a relevância e o desafio do sensus fidei na constituição dogmática Lumen Gentium do Vaticano II / LukasLui; orientadora: Ana Maria Tepedino. - 2010.

148f.; $30 \mathrm{~cm}$

Dissertação (mestrado)-Pontifícia Universidade Católica do Rio de Janeiro, Departamento de Teologia, 2010.

Inclui bibliografia

1. Teologia - Teses. 2. Igreja. 3. Povo de Deus. 4. Católica. 5. Consciência da fé. 6. Fraternidade. 7. Discipulado. 8. Trindade. I. Tepedino, Ana Maria. II. Pontifícia Universidade Católica do Rio de Janeiro. Departamento de Teologia. III. Título. 


\section{Agradecimentos}

A Deus e aos pais, principalmente meu saudoso falecido pai, Petrus P. Betekeneng e minha saudosa falecida avó, Mônika S. Betekeneng.

À professora Dr. Ana Maria Tepedino.

Ao diretor, professores e colaboradores do Programa de Pós-Graduação em Teologia da PUC-Rio.

À comunidade verbita da paróquia Cristo Redentor do Rio de Janeiro.

Aos confrateres, principalmente nossos saudosos frateres falecidos, fr. Servano Leijten e fr. Leopoldo Remans.

Aos colegas. 


\section{Resumo}

Lui, Lukas;Tepedino,Ana Maria A.A Igreja do Espírito de Deus que nasce no coração do povo.A relevância e o desafio do Sensus fidei na Constituição dogmática Lumen Gentium do Vaticano II. Rio de Janeiro, 2010. 148p. Dissertação de Mestrado - Departamento de Teologia, Pontifícia Universidade Católica do Rio de Janeiro.

O presente trabalho disserta sobre duas dimensões da realidade-Igreja: divina e humana, definida pelo Concílio Ecumênico Vaticano II (1962-1965) como Povo de Deus.A Igreja é divina porque tem em Deus sua origem e, humana porque a vontade de Deus é manifestada no coração e na consciência do povo. Concentramos nossa reflexão, especialmente, sobre a relevância e o desafio do sensus fidei na Constituição dogmática Lumen Gentium do Vaticano II. O plano divino é o 'Sim'do amor incondicional de Deus, oferecido à humanidade, e a fé do ser humano é o 'amém'de sua abertura espontânea, a atitude interior de entrega à graça. A consciência da fé é a via necessária, o elemento nuclear e constitutivo da construção de união comunial e relação comunicacional da humanidade entre si, com o cosmos e com Deus. A realidade do povo não-ordenado e sua experiência de Deus no período pósVaticano II se tornaram pano de fundo para os novos cenários da Igreja. Além das atitudes diversas em relação a recepção do Concílio, também há variadas interpretações das abordagens sobre Igreja pós-conciliar. Nossa pesquisa busca analisar esse elemento constitutivo (sensus fidei) da Igreja, utilizando-se fontes teológicas, como: Sagrada Escritura, Tradição e Magistério eclesial.

\section{Palavras-chave}

Igreja; Povo de Deus. Católica; Consciência da fé; Comunhão; Inclusão; Reciprocidade; Fraternidade; Comunidade; Discipulado; Trindade. Corresponsabilidade; Solidariedade. 


\section{Abstract}

Lui, Lukas;Tepedino,Ana Maria A.(Advisor).The Church of the Spirit of God is born in the heart of the people.The relevance and challenge of the "sensus fidei" in the dogmatic Constitution "Lumen Gentium" of Vatican II. Rio de Janeiro, 2010. 148p. MSc.Dissertation - Departamento de Teologia, Pontifícia Universidade Católica do Rio de Janeiro.

This paper talks about two dimensions of Church-reality: divine and human, defined by the Second Vatican Council (1962-1965) as People of God. The church is divine because it has its origin in God and human because God'swill is manifested in the hearts and minds of the people. We focus our thinking, especially about the relevance and challenge of the sensus fidei in the dogmatic Constitution Lumen Gentium of Vatican II. The divine plan is 'Yes' of God's unconditional love, offered to humanity, and faith of the human being is 'amen' of his spontaneous opening, the inner attitude of surrender to grace. The awareness of faith is the necessary road, the core element of the construction and constitution of union communial and communication relationship of humanity with each other, the cosmos and with God. The reality of nonordained people and their experience of God in the post-Vatican II became for the new scenarios of the Church. Besides the diverse attitudes towards the reception of the Council, there are also various interpretations of approaches of the post-conciliar Church. Our research aims to analyze the constitutive element (sensus fidei) of the Church, using theological sources, such as: Holy Scripture, Tradition and Church Magisterium.

\section{Keywords}

Church; people of God; Catholic; Conscience of faith; Communion; Inclusion; Reciprocity; Fraternity; Community; Discipleship; Trinity; Coresponsibility; Solidarity. 


\section{Sumário}

1. Introdução

2. Eclesiologia do Vaticano II

2.1. A natureza essencial da lgreja: dimensão mistérica

2.2. A natureza essencial da Ecclesia: dimensão históricosocial

2.2.1. Breve história da expressão "povo" de Deus desde a sua origem até na véspera do Vaticano II

2.2.1.1. Ochlos

2.2.1.2. Ethnos

32

2.2.1.3. Laos

33

2.2.2. A participação dos batizados-não-ordenados na IgrejaPovo: desafio teológico e pastoral

2.2.3. "Sensus fidei" e a condição dos não-ordenados na Igreja: um desafio da Igreja Povo de Deus

2.2.4. Notas ou propriedades do Povo de Deus

2.2.4.1. A unidade do Povo

2.2.4.2. A santidade do Povo

2.2.4.3. A catolicidade do Povo

46

2.2.4.4. A apostolicidade do Povo

48

2.3. A estrutura organizacional da lgreja: dimensão institucional e hierárquica

2.4. Reinterpretação eclesiológica pós-conciliar: o Sínodo extraordinário de 1985 (José Comblin).

3. "Sensus Fidei" - uma ponte entre academia e hierarquia

3.1. Conceituação

3.2. Estrutura antropológica do crente 64

3.2.1. Ser humano (SH) como ser-em-relação 64

3.2.2. Ser humano ser-em-tensão 66

3.2.3. Ser humano como ser-mistério 69

3.3. Fundamentação teológica do "Sensus Fidei" $\quad 71$

3.3.1. Dados bíblicos $\quad 73$

3.3.2. Dados dos primeiros séculos cristãos $\quad 75$

3.3.3. Os problemas hermenêutico-teológicos $\quad 77$

3.3.4. "Sensus fidei" e/ou "sensus fidelium" no Vaticano II 80

3.3.4.1. Lumen Gentium ( $\left.\mathrm{n}^{\circ} 12 \mathrm{a}\right)$ 
3.3.4.2. Dei verbum ( $\left.\mathrm{n}^{0} .8 \mathrm{~b}\right)$

3.3.4.3. Tensão entre a Tradição e recepção 86

3.4. A importância do "Sensus Fidei" na Igreja povo de Deus 86

3.5. O papel do Sensus Fidei no convívio global da Igreja no mundo em mudança 90

3.6. Resumindo $\quad 92$

4. Igreja povo de Deus no mundo em constante mudança 94

4.1. Desafio missionário e pastoral da Igreja povo de Deus em um mundo em "fuga" acelerada 94

4.1.1. Desafio externo 95

4.1.1.1. Realidade sociocultural/religiosa atual 95

4.1.1.2. Situação socioeconômica 98

4.1.1.3. Questão sociopolítica 100

4.1.2. Desafio interno 100

4.1.2.1. Questão cultural/religiosa e espiritual 101

4.1.2.2. Questão política (gestão interna e externa da ação eclesial) 104

4.1.2.3. Problema da relação de gênero 108

4.1.2.4. Questão da liberdade 112

4.1.2.5. Liberdade como realização da consciência de fé ("sensus fidei" e "sensus fidelium") do Povo de Deus 114

4.1.2.6. Desafio de linguagem 116

4.1.3. Experiência bíblica 118

4.1.4. Consequência pastoral e catequese 124

4.2. Colegialidade da e na Igreja povo de Deus 128

4.3. O papel da sinodalidade na vida da Igreja 131

4.4. Novo jeito de ser Igreja no mundo em contínua transformação

133

$\begin{array}{ll}\text { 5. Conclusão } & 137\end{array}$

6. Referência bibliográfica 140 


\section{Abreviaturas}

AA Decreto sobre o apostolado dos leigos, Apostolicam Actuositate do Concílio Ecumênico Vaticano II.

AG Decreto sobre a atividade missionária da Igreja, Ad Gentes do Concílio Ecumênico Vaticano II.

CD Decreto sobre o Múnus Pastoral dos Bispos na Igreja, Christus Dominus do Concílio Ecumênico Vaticano II.

CDC Código de Direito Canônico.

CNBB Conselho Nacional dos Bispos do Brasil.

DA CONSELHO EPISCOPAL LATINO-AMERICANO -

CELAM. Documento de Aparecida: texto conclusivo da $V$ Conferência Geral do Episcopado Latino-Americano e do Caribe.

DS DENZINGER, Heinrich, Compêndio dos símbolos, definições e declarações de fé e moral.

DSD CONSELHO EPISCOPAL LATINO-AMERICANO. CELAM. Documento de Santo Domingo. Conclusões da Conferência de Santo Domingo: nova evangelização, promoção humana, cultura cristã.

DP CONSELHO EPISCOPAL LATINO-AMERICANO. CELAM. Documento de Puebla. Conclusões da Conferência de Puebla: evangelização no presente e no futuro da América Latina.

DV Constituição Dogmática sobre a Palavra de Deus, Dei Verbum do Concílio Ecumênico Vaticano II.

EN Exortação Apostólica, sobre a evangelização no mundo contemporâneo, Evangelii Nuntiandi do Papa Paulo VI.

GS Constituição Pastoral sobre a Igreja, Gaudium et Spes do Concílio Ecumênico Vaticano II.

LG Constituição Dogmática sobre a Igreja, Lumen Gentium do Concílio Ecumênico Vaticano II.

MS Carta Encíclica sobre o Corpo Místico de Jesus Cristo Mystici Corporisdo Papa Pio XII.

NA Declaração sobre as relações da Igreja com as religiões não-Cristãs, Nostra Aetate do Concílio Ecumênico Vaticano II. 
Po Decreto sobre o ministério e a vida dos presbíteros, Presbyterorum Ordinis do Concílio Ecumênico Vaticano II.

RM Carta Encíclica sobre a validade permanente do mandato Missionário Redemptoris Missio do Papa João Paulo II.

SC Constituição sobre a sagrada liturgia, Sacrosanctum Concilium do Concílio Ecumênico Vaticano II.

SH Ser Humano.

UR Decreto sobre o ecumenismo, Unitatis Redintegratio do Concílio Ecumênico Vaticano II. 